\title{
CORRECTIONS
}

\section{The team physician}

This Editor's Choice (BMJ 2014;348:g2028, doi:10.1136/bmj. g2028) was wrongly attributed to Edward Davies, US news and features editor, $B M J$, when it was in fact written by José $\mathrm{G}$

Cite this as: BMJ 2014;348:92102

Merino, US research editor, $B M J$. 